ISSN: 0514-7336

DOI: http://dx.doi.org/10.14201/zephyrus20157585105

\title{
EL DOLMEN DEL MILANO Y LA ARTICULACIÓN TERRITORIAL DEL FENÓMENO MEGALÍTICO EN EL ÁREA DE BARCARROTA (BADAJOZ)
}

\section{The dolmen of El Milano and the territorial articulation of the megalithic phenomenon in the Barcarrota's area (Badajoz)}

\author{
Juan Javier EnRíquez Navascués y David M. Duque Espino
}

Grupo PRETAGU. Dpto. de Historia. Facultad de Filosofía y Letras-UnEX. Campus Universitario, s/n. 10071 Cáceres. Correo-e: enriquez@unex.es; despino@unex.es

Recepción: 4/06/2014; Revisión: 6/02/2015; Aceptación: 14/04/2015

BIBLID [0514-7336 (2015) LXXV, enero-junio; 85-105]

\begin{abstract}
Resumen: El objetivo del presente trabajo es presentar los resultados generales de la excavación del dolmen del Milano, su integración territorial en el área megalítica de Barcarrota y la caracterización espacial que presenta la implantación dolménica en este espacio geográfico. La metodología empleada para el estudio territorial se ha basado en el análisis espacial del paisaje en que se sitúan los dólmenes registrados y catalogados, pero también de los tholoi y poblados calcolíticos que se conocen en esa zona. Las conclusiones sugieren la importancia que tuvieron algunas variables, en especial la hidrográfica, pues las agrupaciones de dólmenes se sitúan en el nacimiento de las cuencas fluviales, así como las vías de comunicación intercomarcal que la atraviesan. Menor importancia parece que tuvieron otras, como el potencial o capacidad del suelo y la topografía. Pero un panorama diferente es el que se detecta en la disposición que presentan los tholoi y los poblados calcolíticos, donde predominan otros criterios de ubicación diferentes, como son la fertilidad del suelo, la ocupación de altos estratégicos y la articulación de los mismos en el eje de la cuenca del río Olivenza.

Palabras clave: Resultados de excavación; estudio paleoambiental; integración; análisis espacial.
\end{abstract}

Aвstract: The aim of this paper is to present the overall results of the excavation of the dolmen of El Milano, territorial integration in the megalithic area Barcarrota and spatial characterization having the dolmen implementation in this geographical area. The methodology used for territorial study was based on the spatial analysis of landscape in the dolmens are located registered and cataloged, but also the tholoi and Chalcolithic settlements known in this area. The findings suggest the importance they have some variables, especially the hydrographic, as dolmens groups are at the birth of river basins, as well as inter-geographical regions routes of communication that cross. Minor seem to have had other, as the potential or capacity of soil and topography. But a different picture is presented by tholoi and Chalcolithic settlements, where other criteria predominate different location, such as soil fertility, the occupation of strategic high and articulating them on the shaft river basin Olivenza.

Key-words: Excavation results; paleoenvironmental study; integration; spatial analysis.

(C) Universidad de Salamanca

Zephyrus, LXXV, enero-junio 2015, 85-105 


\section{Características generales del dolmen del Milano}

El Milano es el dolmen más monumental del núcleo megalítico del entorno de la localidad de Barcarrota, en la provincia de Badajoz (Fig. 1), donde la existencia de este tipo de estructuras es conocida desde el s. XIX, con una primera catalogación de las mismas efectuada en los inicios del s. xx por J. R. Mélida (1914, 1924 y 1925). No obstante, pese a tratarse de un destacado conjunto, como ya ha sido reiterado (Bueno, 2002: 58), se carece de investigaciones sistemáticas como las desarrolladas en otras áreas vecinas extremeño-alentejanas, de manera que solamente algunas plantas, fotografías y materiales han sido dados a conocer (Mélida, 1914,

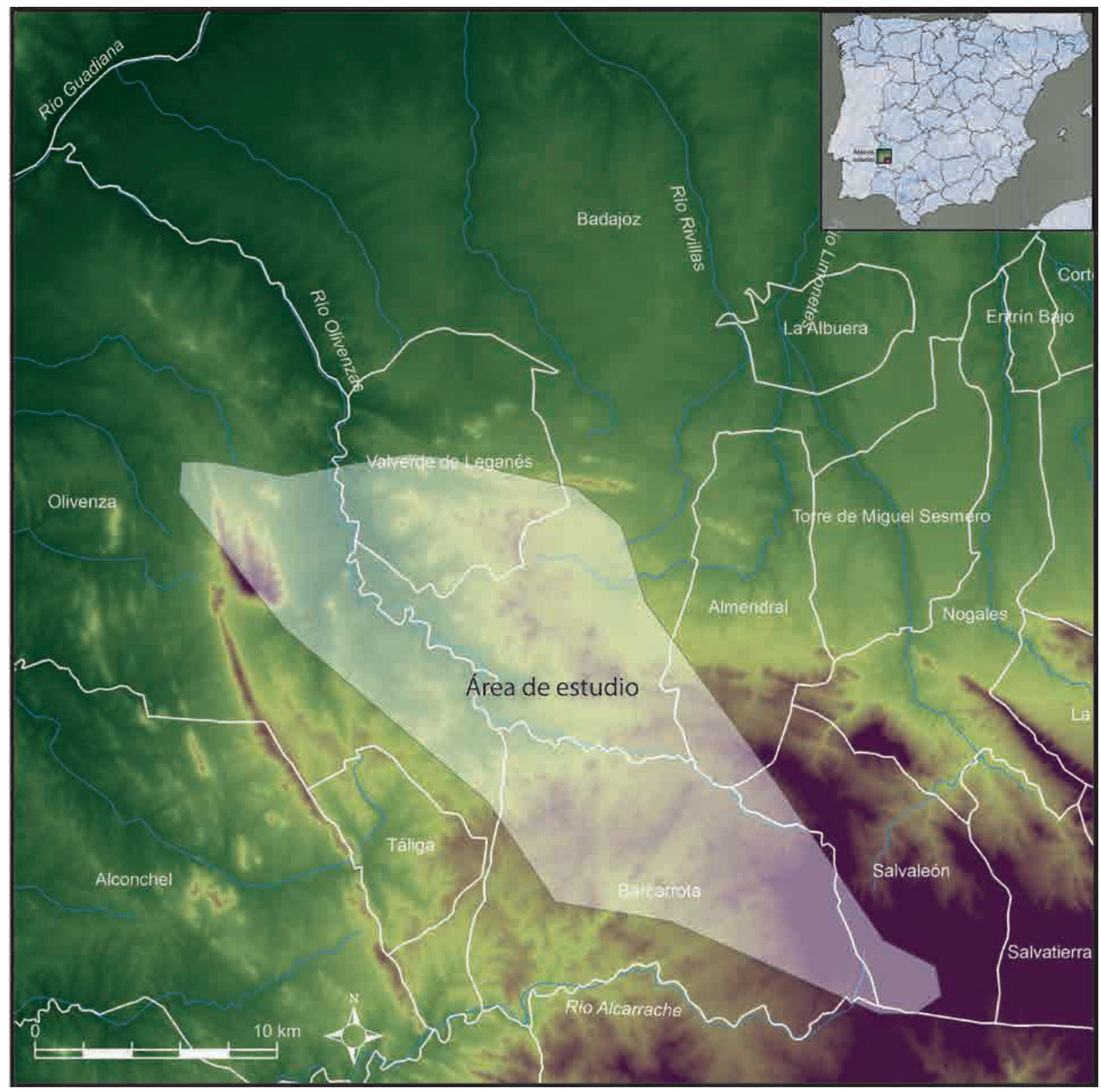

FIG. 1. Situación geográfica del área de Barcarrota (Badajoz). 
1924 y 1925; De los Santos, 1939; Leisner, 1959; Bueno, 1987 y 2002; Sanjuán, 2006). En concreto, este dolmen del Milano fue descrito tanto por Mélida como por los Leisner, pero cuando Mélida lo visitó, en octubre de 1924, se encontraba ya muy arruinado (Mélida, 1924: 134). No obstante, señaló un diámetro de 3,60 m para la cámara poligonal de 7 ortostatos y 6,25 m de longitud para el corredor (Mélida, 1925: 45-46). Los Leisner por su parte recogieron que se trataba de una cámara poligonal de 3,70 x 4,50 $\mathrm{m}$ de diámetro compuesta por 7 ortostatos de granito, con el corredor muy perdido (Leisner, 1959: 309).

Ambas descripciones y la documentación gráfica que las acompaña son las referencias que se han venido utilizando de manera habitual desde entonces, mientras con el paso de las décadas se iba acentuando el deterioro del dolmen. Por ello, hace unos años, $y$ ante el estado ruinoso que presentaba, el Ayto. de Barcarrota instó a la Junta de Extremadura a que actuase para su preservación. El resultado de sus gestiones fue la ejecución de un proyecto de consolidación del dolmen por parte de la Consejería de Cultura de la Junta de Extremadura, dentro de cuyo marco tuvo lugar una
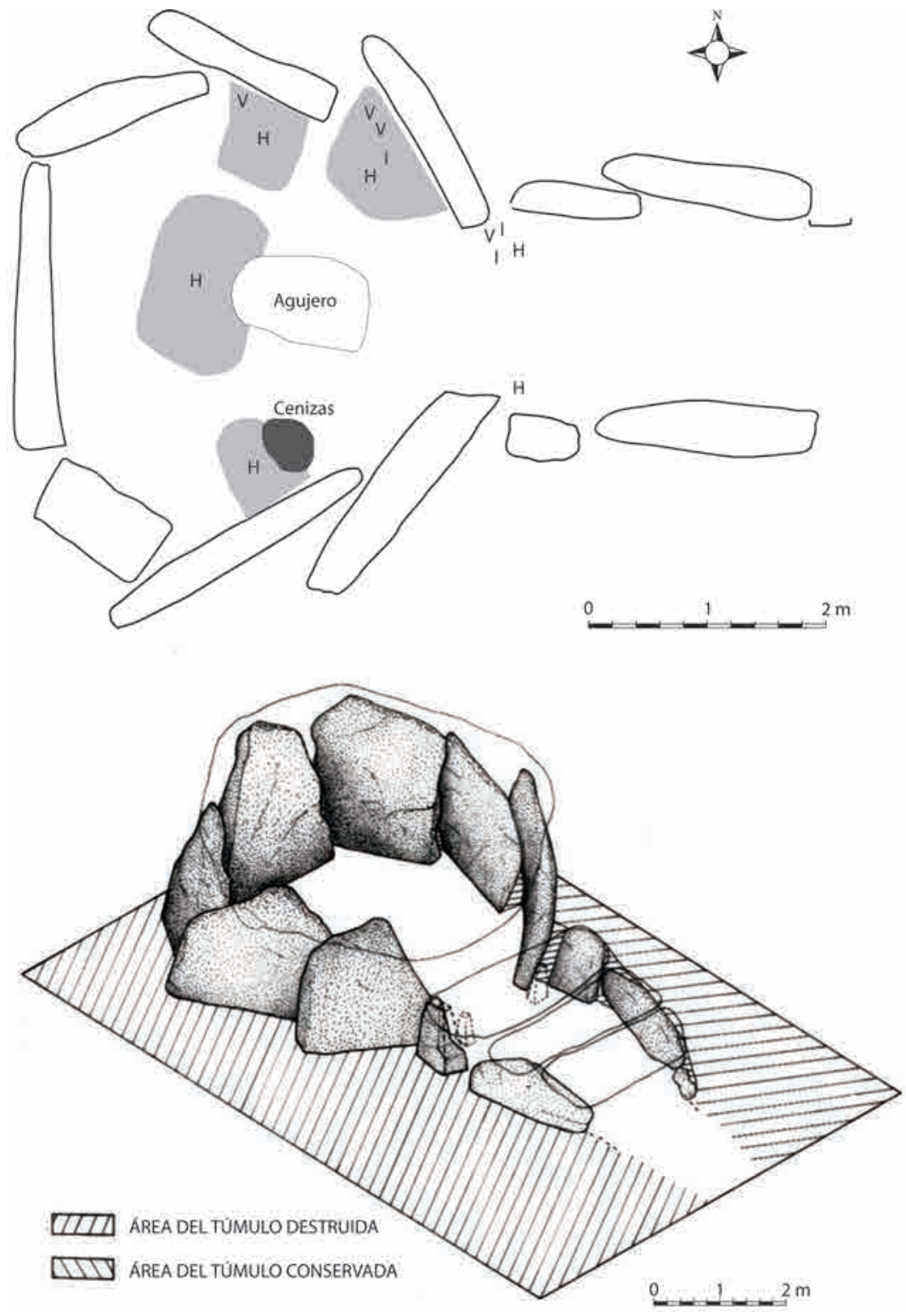

Fig. 2. Planta y reconstrucción isométrica del dolmen del Milano. intervención arqueológica previa. Aunque dicho proyecto de consolidación no ha llegado a concluirse del todo, sí que pudo efectuarse la excavación de la cámara y de los restos del corredor, consolidar los ortostatos que estaban rotos y caídos evitar la desaparición de los pocos vestigios del túmulo que aún no habían sido arrasados.

La excavación efectuada permitió documentar una cámara de 7 ortostatos de granito orientada al

E (Hoskin y Sauch, 1999: fig. 6, tabla 2), con 3,60 $\mathrm{m}$ en el eje E-O por 4,20 m en el N-S así como restos del corredor (Fig. 2). Este se halló conservado en una longitud de $2,80 \mathrm{~m}$ a partir de la cual sólo mantenía algunas trazas muy deterioradas de las cajas de cimentación de otras piedras del mismo. Algunos ortostatos desplazados pertenecieron a la cubierta de este corredor bajo, dispuesto con dos piedras 
verticales en el inicio seguidas de otras en disposición horizontal. En la intersección entre la cámara y el corredor se hallaron dos jambas de diorita. La cubierta de la cámara, con un peso de más de 12 toneladas, se encontraba fracturada y caída sobre el interior de la misma y el arranque del corredor al menos desde la visita de Mélida (1925: fig. 36).

El relleno de la cámara se encontró muy revuelto debido a diversas reutilizaciones de la estructura y a episodios de rebuscas, que no llegaron a afectar a todo el interior. Así en ciertos puntos concretos se detectó un nivel de piedras medianas colocadas horizontalmente de manera regular, debajo del cual hicieron su aparición restos óseos, sin conexión anatómica alguna, mezclados con fragmentos de ídolos-placa y cerámicas. En total fueron 4 los conjuntos de materiales detectados en un estrato irregular de entre 20 y $40 \mathrm{~cm}$ de espesor que apoyaba en una capa rojiza que contactaba con la roca madre (Fig. 2). Esos conjuntos eran desiguales en cuanto a su composición y área de extensión, pero de estructuración similar: amasijos de huesos y restos de ajuar que se encontraban sobre la capa rojiza que cubría el suelo de la cámara y bajo una línea de piedras medianas que los aislaba del revuelto superior. La deposición aparente de estos conjuntos no era, sin embargo, cuidadosa, sino que los huesos, fragmentos de ídolos placa, cerámicas, etc., formaban amasijos que habían sufrido diversos procesos postdeposicionales y la propia presión del relleno superior. También en el corredor, en el lateral s y bajo un fragmento desplazado de la piedra de cubrición de la cámara, aparecieron otros huesos junto a fragmentos de ídolos placa y dos vasitos completos (Fig. 2).

Tanto los rasgos arquitectónicos como los elementos materiales de ajuar recuperados resultan muy característicos y habituales del fenómeno dolménico extendido por las actuales regiones del Alentejo portugués y la Extremadura española. Dentro de los primeros no es inusual la presencia de distintas clases de piedras en la construcción, pues si bien se han utilizado granitos bastante homogéneos provenientes de unos afloramientos situados a 300 $\mathrm{m}$ al No, ya se ha referido como las dos piedras que sirven de jambas entre cámara y corredor son de diorita, materia prima que no existe en del entorno mismo del Milano, aunque sí en zonas más alejadas. Respecto a los ajuares, se hallaron vasos cerámicos pequeños, algunos de ellos completos, útiles tallados y pulidos e ídolos placa muy característicos, la mayoría fragmentados pero algunos enteros. Destacan los ídolos placa con decoración de distintas combinaciones de motivos geométricos, que los acercan a otros ejemplares conocidos de la zona de Barcarrota (De los Santos, 1939) y que no están exentos de cierta personalidad (Bueno, 1992). Por su parte, los restos óseos se encuentran actualmente en estudio pero está clara la presencia de huesos pertenecientes a ambos sexos y la correspondencia de los mismos a distintos grupos de edad.

Por otro lado, del contenido de tres vasos cerámicos se efectuaron análisis polínicos ${ }^{1}$ destacando en términos de posible carácter ritual el resultado de uno de ellos con un 99,83\% de los palinomorfos correspondientes a Muscari neglectum, una flor silvestre de primavera conocida como 'nazareno' y también, curiosamente, como 'cebollica' o 'cebollica de milano'. Su casi exclusiva presencia en ese vaso, que se localizó en la base misma del monumento, podría plantearse como los restos de una ofrenda floral relacionada con el primer momento de uso de la construcción.

La escasa información palinológica de los tres vasos en conjunto nos remite a un paisaje vegetal abierto dominado por especies herbáceas relacionadas con un ambiente muy nitrificado -Urticaceae, Amaranthus sp. y Rumex sp.- fruto, tal vez, de las actividades agropecuarias desarrolladas por los grupos humanos que construyeron estos dólmenes. En este sentido, la relevancia palinológica que adquieren Poaceae, Astaraceae y Muscari, esta última asociada en nuestras latitudes a campos de cultivos, y algunas malas hierbas y la presencia de cebada vestida (Hordeum vulgare) en el registro carpológico ${ }^{2}$ permiten vislumbrar esa economía de base agropecuaria.

Complementando a estos paisajes netamente antrópicos, las analíticas palinológicas y antracológicas ${ }^{3}$ nos revelan la importancia de especies arbustivas y de matorral-leguminosas, lentiscos, rosáceas maloideas

1 Blanco Salas, J. y Vázquez Pardo, F. M.: "Informe sobre análisis de muestras paleopalinológicas. Dolmen del Milano. Barcarrota. Badajoz”. Informe inédito.

2 Pérez Jordá, G.: "Informe de los restos carpológicos del dolmen del Milano (Barcarrota, Badajoz)". Informe inédito.

3 Duque Espino, D. M.: La gestión del paisaje vegetal en la Prehistoria Reciente y Protohistoria en la Cuenca Media del Guadiana a partir de la Antracología. Tesis doctoral inédita presentada en 2004 en la Univ. de Extremadura. 
y prunoideas, acebuches, cistáceas y torviscos-, sustitutivas de las formaciones mixtas de quercíneas documentadas-Quercus sp. t. caducifolio y $Q$. ilex-coccifera-. Formaciones mixtas y complejas que contrastan con la actual predominancia y monoespecificidad de los encinares de esta zona (Devesa, 1995), a los que se sumaría un dosel ripario estructurado en torno a fresnos, chopos, adelfas, narcisos y algunas plantas acuáticas como Nuphar sp., dejando entrever un ambiente más húmedo y atlántico en la antigüedad que el continental y meso/ termo-mediterráneo actual, tal y como se pone de manifiesto en otras áreas geográficas vecinas con manifestaciones megalíticas (Allué, 2000; Duque, 2002, 2005a, 2005b y 2006"; Figueiral, 1998; López García, 1994; Queiroz, 2001).

\section{Aproximación a la definición de los grupos territoriales del área megalítica de Barcarrota}

Uno de los aspectos que suscita mayor interés en la consideración del dolmen del Milano es su integración territorial en el área megalítica de Barcarrota, de manera especial porque el modelo de implantación que presenta se repite con muy parecidas características dentro de la misma.

Esta área (Figs. 1 y 3) tiene su límite septentrional en los llanos que van de Olivenza a $\mathrm{La} \mathrm{Al-}$ buera, tierras bajas de suelos predominantemente terciarios y cuaternarios en contacto directo con el valle del Guadiana. Por el e en la comarca de Tierra de Barros y al o en las sierras de Alor y de las Puercas, que dan paso a la ribera del río Táliga y a la penillanura que llega hasta la margen izquierda del Guadiana. Al s en el arco que forman las estribaciones de Sierra Morena a la altura de Salvaleón e Higuera de Vargas, coincidiendo con las sierras que delimitan la cuenca de río Ardila, con un paisaje típicamente serrano. Constituye así un pasillo entre el valle del Guadiana y las estribaciones de Sierra Morena occidental, pero encajado entre dos franjas más por las que discurren las principales vías de comunicación $\mathrm{N}$-s desde al menos el s. XIX, la más occidental cerca del Guadiana y la oriental a través de Tierra de Barros hasta el punto nodal de Zafra. Desde el punto de vista administrativo se

\footnotetext{
${ }^{4}$ Cf. también op. cit. n. 3.
}

extiende por los términos municipales de Valverde de Leganés, sur del de Badajoz, Almendral, Salvaleón y Barcarrota, en una extensión aproximada de $284 \mathrm{~km}^{2}$.

Geológicamente se integra en la Zona Ossa Morena, dentro del anticlinorio Olivenza-Monesterio. Destacan los materiales precámbricos y del Cámbrico inferior, con un especial protagonismo de esquistos, pizarras y grauvacas con horizontes esporádicos de cuarcitas negras. Por otro, los efectos del plegamiento herciniano que generó diversas plataformas graníticas entre las que tienen mayor relevancia el llamado 'batolito de Barcarrota' y el más reciente macizo granítico de Almendral, denominado también de Valverde. En el primero se trata de granitos alcalinos y granodioritas sobre todo $\mathrm{y}$ en el de Almendral/Valverde de sienitas (Muelas y Soubrier, 1977: 30-31).

Los suelos corresponden al tipo pardo meridional sobre granitos y pizarras y litosuelos, de escasa potencia y limitada capacidad de explotación, salvo en puntos determinados con suelos más arcillosos. De $\mathrm{N}$ a s la orografía se va elevando suavemente desde los $250 \mathrm{~m}$ junto a los llanos de Olivenza a los más de 650 de los altos meridional de Barcarrota y Salvaleón. La red hidrológica presenta en la zona el nacimiento de importantes cursos fluviales de la red secundaria del Guadiana, además de una multitud de arroyos y riveras. $\mathrm{Al} s$ nace el río Alcarrache, que se desarrolla hacia el so; un poco más al $\mathrm{N}$ de este surge el río Olivenza, que discurre al no y vertebra prácticamente el espacio del área señalada hasta su llegada a los llanos de Olivenza. En el sector NE las cuencas de los ríos Limonetes y Rivillas con dirección $\mathrm{N}$ al tramo final de las Vegas del Guadiana.

Para la definición territorial del fenómeno megalítico de esta zona y su evolución posterior se ha utilizado el software ArcGis 9.3. En él hemos introducido una serie de cartografía básica como el Modelo Digital del Terreno -en adelante MDT- con una escala de $25 \mathrm{~m} /$ pixel proporcionada por el Instituto Geográfico Nacional -en adelante IGN-, la red hidrográfica vectorial de la Confederación Hidrográfica del Guadiana -en adelante CHG- en la que ha resultado clave la información de los límites de cuencas y subcuencas contenidos en la misma, tal y como ha resultado en otros estudios de áreas megalíticas cercanas (López-Romero, 2007) y los mapas geológicos de la serie MAGNA del Instituto 


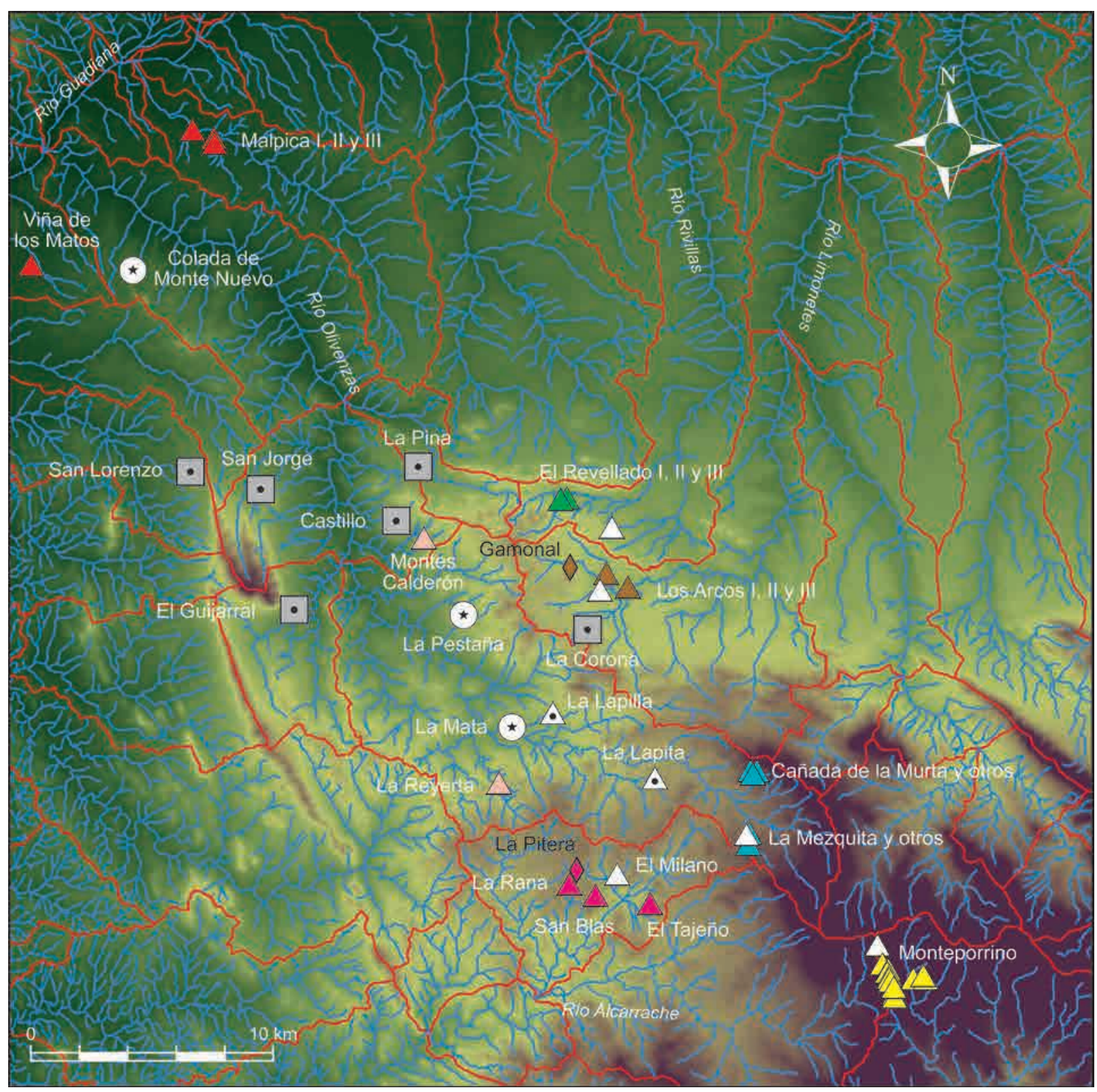

Fig. 3. Situación geográfica de los dólmenes $(\mathbf{\Delta})$, menhires $(\checkmark)$, tholoi $(\star)$ y poblados calcoliticos $(\bullet)$ del área de estudio y su reborde septentrional.

Geológico y Minero de España -en adelante IGMEa escala 1:50.000 (Hojas n. ${ }^{\circ} 801,802,827,828$, 852 y 853). Todo ello nos ha permitido aproximarnos a la definición orográfica, hidrológica y edafogeológica de la zona de estudio y de esta forma poder calibrar la diversidad de ubicaciones de los sitios megalíticos con respecto a estos factores.
La localización de los sitios arqueológicos se ha llevado a cabo mediante el rastreo de las coordenadas publicadas en la bibliografía existente, las proporcionadas por la Carta Arqueológica de la Dirección General de Patrimonio de la Consejería de Educación y Cultura del Gobierno de Extremadura, reconocimientos de campo y los puntos 
indicados en la cartografía vectorial 1: 25.000 de este espacio del IGN. Todo ello además ha sido contrastado mediante su reconocimiento en las ortoimágenes de máxima resolución proporcionadas por el IGN en la medida de lo posible.

Con todas estas localizaciones arqueológicas hemos elaborado dos sencillas bases de datos espaciales del área de estudio, una para el fenómeno megalítico y otra para las evidencias calcolíticas. Dentro de la primera se han incluido dos variables: 'Tıро', que hace referencia a la tipología megalítica cuando ésta ha podido ser concretada, y 'GRUPO', en la que se ha contemplado la red hidrológica. Esta primera aproximación nos ha permitido categorizar tipológica y espacialmente el conjunto de construcciones megalíticas generando una primera clasificación territorial del mismo: grupo del Milano o cabecera del río Alcarrache, grupo del río Olivenza, grupo de la cabecera del río Limonetes, grupo de la cabecera del río Rivillas y grupo dehesa de Monteporrino, más otras localizaciones puntuales y dispersas en el área de estudio cuya definición territorial resulta complicada con el nivel de información con el que contamos a día de hoy. La definición de estos primeros grupos, sin embargo, mostraba mezcla de patrones tipológicos y territoriales que debían ser depurados. Para ello hemos recurrido al cálculo de las visibilidades acumuladas y las áreas de influencias mediante la poligonación de Thiessen que nos han permitido reorganizar algunas de las primeras agrupaciones en subgrupos o unidades menores.

Las visibilidades acumuladas se han calculado utilizando los recortes del MDT de las áreas de captación de recursos hipotéticas, estimadas en 5 $\mathrm{km}$ para los dólmenes de corredor largo con o sin cámara monumental -Milano, Mezquita, Lapita, Lapilla, Revellado I, Romo, Monteporrino 1 y para el caso de los aislados Reyerta y Montes Calderón-, y todas las evidencias megalíticas -dólmenes y menhires- incluidas en cada área, estimando la altura del observador en $1,75 \mathrm{~m}$. El resultado general muestra que, a pesar de compartir espacios de sus respectivas áreas de captación, los campos visuales finalmente obtenidos parecen individualizar los grupos ya considerados. En un sentido similar se muestra el cálculo de las áreas de influencia del conjunto de manifestaciones megalíticas en el que hemos tenido en cuenta el total de las mismas, tomando como límite de la poligonación obtenida las áreas de captación de recursos de las arquitecturas significadas por su corredor largo.

En función del resultado de estas dos variables: visibilidad y áreas de influencia y la alta correspondencia que presentan, hemos establecido las unidades territoriales que a continuación pasamos a describir teniendo en cuenta para cada unidad los siguientes factores de análisis: geología, sedimentología, hidrología, fertilidad del suelo, visibilidad, áreas de influencia, caminos y veredas, tipos de arquitecturas, tamaño y ubicación de las mismas.

\subsection{El dolmen del Milano y el conjunto de la cabecera del río Alcarrache}

La interrelación de los citados factores nos muestra como la integración territorial del Milano permite definir un grupo compuesto además por los dólmenes de Tajeño, la Rana y San Blas (Fig. 4), todos sobre granitos alcalinos, cerca del contacto con los biotíticos de grano grueso y los de cuarzosienita. El conjunto incluye el menhir partido en dos de la Pitera, que mide 4,35 $\mathrm{m}$ de largo por 1,35 $\mathrm{m}$ de ancho y presenta un extremo apuntado. Estos megalitos dejan libre el pasillo de granodioritas por el que discurre el arroyo de la Dehesa, en cuya margen izquierda está el Tajeńo y en la derecha los otros tres.

En concreto el Milano se localiza $5 \mathrm{~km}$ al o de la localidad de Barcarrota, en una suave pendiente a $390 \mathrm{~m}$ de altitud junto a un curso de agua tributario del arroyo de Rodríguez, dentro de la cuenca del río Alcarrache. En sus inmediaciones es importante la presencia de una serie de fuentes y veneros. En la margen derecha del arroyo del Álamo están la Rana y San Blas. El primero es de pequeño tamaño y se localiza en una zona suavemente alomada a $429 \mathrm{~m}$ de altitud junto al cordel del Alcarrache, de la $\mathrm{Ca}$ ñada Real Meseteña. También el de San Blas es de tamaño más pequeño que el Milano, con cámara que no supera los $3 \mathrm{~m}$ de diámetro máximo (Mélida, 1924: 132), pero está en un pequeño rellano de una ladera a $420 \mathrm{~m}$. Así mismo en la ladera de otra loma en la margen izquierda de la cuenca se localiza Tajeño, a $415 \mathrm{~m}$ de altitud. El más monumental es por tanto el Milano, situado en la cota más baja de las cuatro, con una visibilidad puntual que hace que sólo sea perceptible desde la cercanía. 


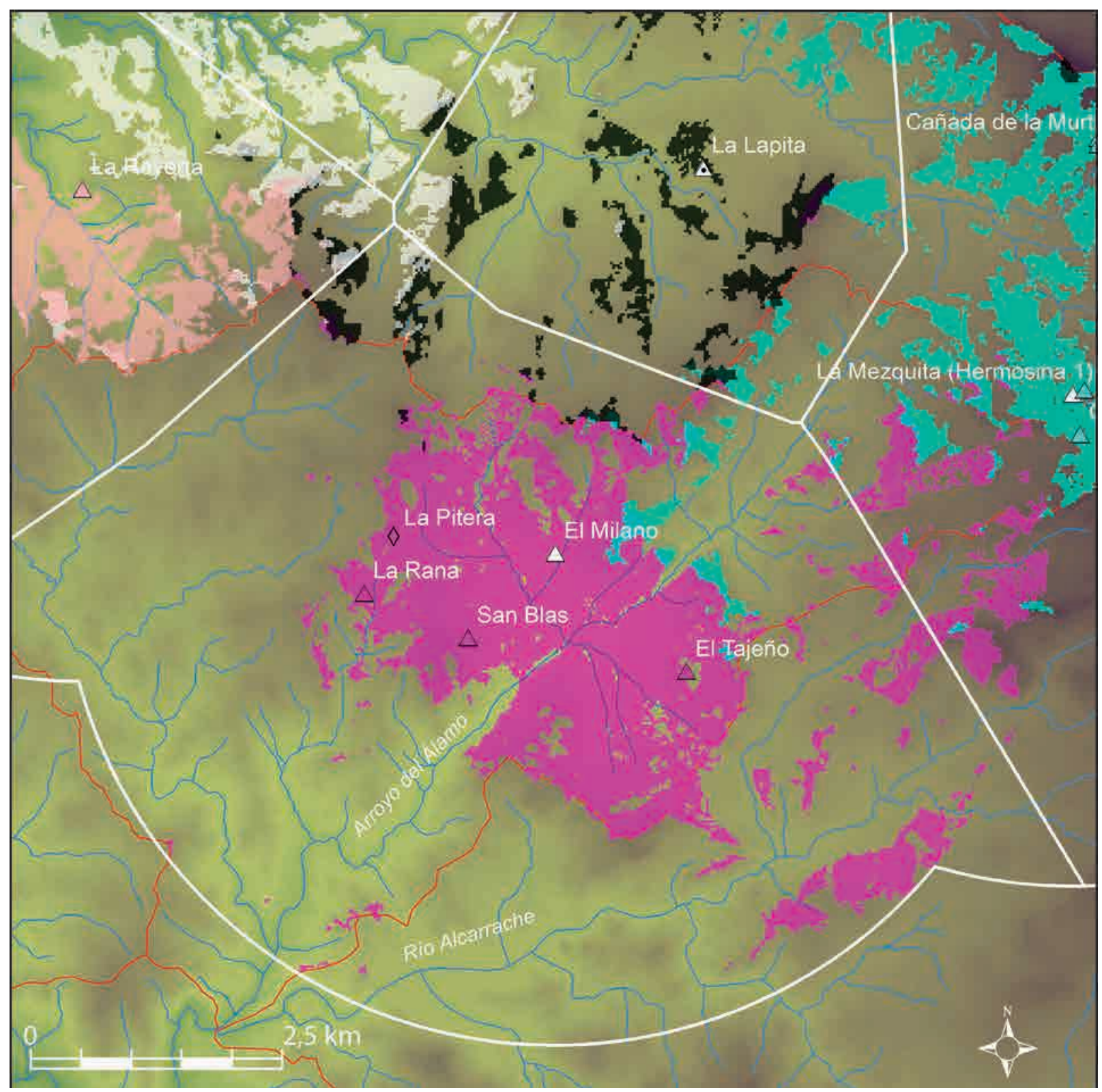

FIG. 4. Territorialidad hipotética del grupo de la cabecera del rio Alcarrache.

Esta agrupación se dispone por tanto en la cabecera de la cuenca del Alcarrache, articulada en torno a las corrientes del arroyo del Álamo (Fig. 4), que en dirección so desemboca en el citado río. Es una zona de contacto entre distintos tipos de granito, en la que se define un espacio visual particular, que otorga al Milano una posición central y que integra intervisibilidad teórica entre los cuatro dólmenes. El área de influencia teórica de éstos se extiende fundamentalmente por la cuenca del Alcarrache, hacia el espacio por el que discurre el llamado 'Cordel del Alcarrache'. Aparece así como un grupo bien individualizado, jerarquizado en principio con el Milano como el más monumental y el único de visibilidad puntual, que como tal agrupación está bien separado de los más cercanos 
dólmenes de la cuenca del río Olivenza, como la Mezquita 1, la Lapita y la Reyerta y al SE de los de Monteporrino (Figs. 3 y 4).

Este modelo de implantación de un corto número de dólmenes agrupados y dispuestos en la cabecera de una cuenca fluvial, con uno de ellos más destacado, campos visuales y visibilidad limitada, áreas de influencia teórica muy similares y cercanía de vías locales de comunicación, se repite en el área de Barcarrota en el nacimiento de los cursos de agua más importantes que surgen en ella.

\subsection{Los dólmenes de la cabecera del río Olivenza}

En el nacimiento de la cuenca del río Olivenza, sobre un sustrato de gabros anfibólicos, cerca de la presencia de granodioritas, encontramos dos subgrupos de dólmenes. Ambos se ubican junto a la ribera del Fraile, uno en cada margen (Fig. 5). En la izquierda el que forman la Mezquita 1, Cabezo Terrazo y Hermosina 2. En la derecha, entre el arroyo del Palacio y la sierra de los Gavilanes, otros tres: Cañada de la Murta, Enmedio y Mezquita 2, también llamado el Palacio.

En la margen izquierda destaca la Mezquita 1, otro dolmen de corredor largo con más de 3,5 m de diámetro en cámara (Mélida, 1925: 45 y fig. 30), situado a $510 \mathrm{~m}$ de altitud. En el corredor se utilizaron pizarras y cuarzos, siendo el resto granitos (Bueno, 1987: 78). A $350 \mathrm{~m}$ en dirección sur está Cabezo Terrazo y cerca el de Hermosina 2, que parece igualmente de tamaño menor. El grupo de la margen derecha forma una especie de triángulo junto al camino de Salvaleón a Olivenza, en cotas de $510 \mathrm{~m}$ para el pequeño del Palacio y los $540 \mathrm{~m}$ del de Enmedio. El estado de conservación en que se encuentran no permite ni comprobar ni ampliar los datos transmitidos por Mélida, que para el de Cañada de la Murta apuntaba más de $3 \mathrm{~m}$ de diámetro en la cámara (Mélida, 1925: 47), el mayor en principio del grupo. Al margen de una posible jerarquización entre ellos, como parece también ocurrir en las otras agrupaciones, parece claro que a nivel mesoespacial se ubican en un punto estratégico del paso entre la sierra Gavilanes -661 m- y la penillanura por la que discurren los cursos de agua que dan lugar a la cabecera de la ribera del Fraile y al nacimiento de la cuenca del río Olivenza.
Ambas agrupaciones distan entre sí $2,5 \mathrm{~km}$ en línea recta y, según la percepción del campo visual teórico de uno y otro subgrupo (Fig. 5), serían intervisibles. Además se trata de campos visuales abiertos hacia la cuenca del Olivenza y más cerrados al N, s y E, es decir, con una visibilidad sectorial hacia la citada cuenca. Los dólmenes del subgrupo de la Cañada de la Murta están en relación directa con el antiguo camino de Salvaleón a Olivenza, mientras los de la Mezquita 1 se ubican junto al de Salvaleón a Barcarrota, por un terreno más llano. Ambos debieron confluir en el pasillo que forman las riberas del Olivenza, donde vienen a coincidir sus respectivas áreas de influencia teórica. Estas variables territoriales apuntan así a su consideración como un mismo grupo, estructurado en dos pequeños conjuntos.

\subsection{Los dólmenes del curso medio del rio Olivenza}

Aguas abajo se encuentran dos dólmenes más: la Lapita y la Lapilla (Fig. 3). El de la Lapita está en la margen izquierda del Olivenza, entre el arroyo del Fraile y el arroyo de la Lapita, en un terreno llano adehesado que no supera los $420 \mathrm{~m}$ y que geológicamente corresponde a cuarzosienitas cataclásticas. Es otro dolmen de corredor largo, y no corto como a veces se ha recogido, según se pudo comprobar en una limpieza superficial que se hizo. Pero la cámara no alcanza los $3 \mathrm{~m}$ de diámetro máximo y la estructura megalítica en su conjunto es sensiblemente menos monumental que la del Milano, Mezquita 1 y otros de la zona como el Romo. No presenta gran visibilidad, pero el campo visual desde él marca un espacio que viene a coincidir con el que se obtiene en el cálculo de su área de influencia teórica más inmediata (Fig. 8). Por tanto no está ligado visualmente a ningún otro dolmen o conjunto de ellos y ni siquiera el sustrato geológico es el mismo que el de los más cercanos. A su alrededor puede individualizarse así un territorio amplio, con límites bastante nítidos que no entran en conflicto aparente con los referentes paisajísticos que lo separan de los dólmenes vecinos. Estos factores junto a las variables relativas a su arquitectura, tamaño y ubicación, a propósito de las cuales destaca su menor monumentalidad respecto a los dólmenes de corredor largo de las agrupaciones, aunque coincide con ellos 


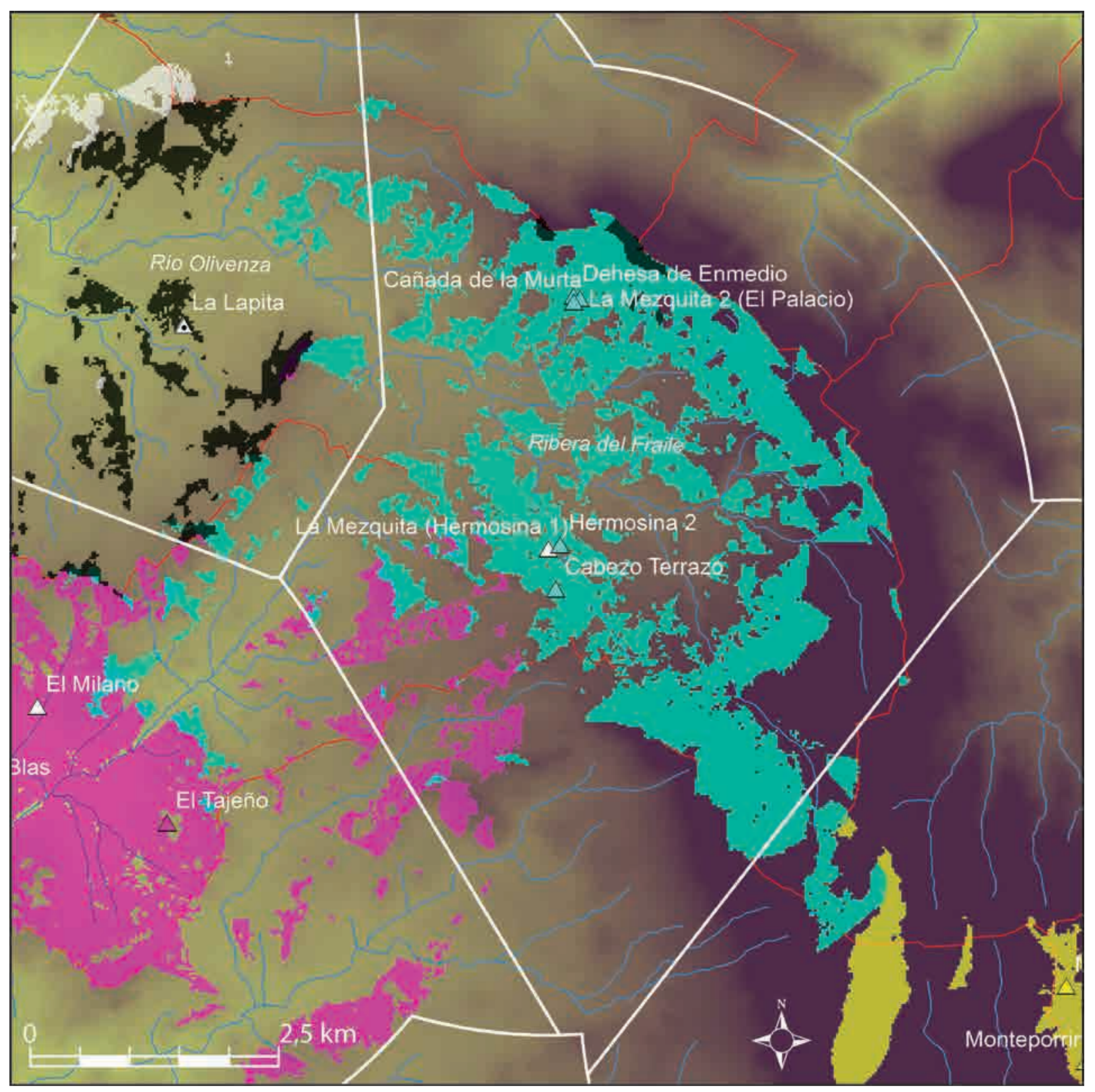

FIG. 5. Territorialidad hipotética del grupo de la cabecera del río Olivenza.

en su visibilidad puntual, tienen como consecuencia su independencia territorial respecto al grupo Mezquita 1-Cañada de la Murta, al del Milano y demás megalíticos limítrofes (Fig. 8). La gran incógnita es si cronológicamente es contemporáneo de todos o algunos de los dólmenes agrupados y, de serlo, si podría explicarse su carácter individual por el hecho de que tal vez la disposición de las sepulturas, y algunos rasgos arquitectónicos, fueran diferentes una vez rebasado el tramo alto de las cuencas de los ríos.

En la margen derecha del Olivenza, entre arroyos también, está el de la Lapilla, con un diámetro de la cámara en torno a los $3 \mathrm{~m}$ y un corredor descentrado de poco más de $5 \mathrm{~m}$, según recoge Fernández Caballero basándose en datos de Bueno Ramírez (Fernández Caballero, 1999: 28). Está 
dentro del pasillo formado por esquistos y grauvacas con afloramientos de cuarcitas de la serie negra. No obstante, $250 \mathrm{~m}$ al o existe un afloramiento de granito biotítico y un poco más lejos, a $350 \mathrm{~m}$, otro de gabros anfibólicos. Su caso es muy similar al de la Lapita. Su arquitectura, tamańo, visibilidad, campo visual y área teórica de influencia le separan de la Reyerta y del grupo del Romo, que en distintas direcciones son los más cercanos (Fig. 8). Aquí también puede definirse una territorialidad individualizada, que sigue los parámetros de la Lapita y que tal vez explique la razón de no situarse sobre los cercanos substratos graníticos.

Otros dos dólmenes más se conocen en el curso medio del río Olivenza (Fig. 3), ambos aparentemente asilados (Fernández Caballero, 1999: 31 y 40). Al so, en la margen izquierda de la cuenca, se localiza el de la Reyerta, en un terreno de granito biotítico, que presenta un deteriorado estado de conservación. Aguas abajo, en la margen derecha, dentro de la zona granítica de Valverde de Leganés se encuentra el dolmen de Montes Calderón, con una ubicación en alto y pese a su estado de ruina con indicios del arranque del corredor.

\subsection{Los dólmenes de la cabecera del río Limonetes}

Se trata de otros tres dólmenes: el Romo, Campillo 1 y Campillo 2, denominados también en ocasiones como Los Arcos 1, 2 y 3 respectivamente por su cercanía al castillo de los Arcos, en el término de Badajoz (Fig. 6). A una distancia de $1485 \mathrm{~m}$ del Romo se encuentra el menhir en granito de Gamonal, fusiforme con los extremos apuntados que alcanza los 4 $\mathrm{m}$ de longitud. Estos cuatro elementos son los únicos que están en el macizo granítico de cuarzosienitas alcalinas que hay entre Almendral y Valverde, en una zona de regatos y arroyos que, a través de la ribera de la Pizarra y de la del Chicapiedras, tienen su salida de aguas hacia el $\mathrm{N}$ por el río Limonetes. Éste llega a las Vegas del Guadiana por la localidad de La Albuera.

El más destacado es el del Romo, en medio de un terreno llano cercano al arroyo Gamonal y al arroyo de la Cinchosa, considerado de corredor largo y con 3,6 m de diámetro en la cámara (Mélida, 1925: 43). De menores dimensiones es el de Campillo 1, cerca del arroyo Arganzano, del que se aprecian restos de corredor, y muy destruido está el de Campillo 2, también en llano y al E del castillo de los Arcos. El análisis del campo de visión muestra que entre ellos existe intervisibilidad teórica, mientras el área de influencia muestra una complementariedad en un territorio muy similar, en consonancia en este caso con el sustrato geológico y sedimentológico, bien separado de la cuenca del Olivenza (Fig. 6). Ofrece así una ubicación topográfica en llano, junto al nacimiento de cursos de agua que van hacia el $\mathrm{N}$, en este caso al arroyo Limonetes que es tributario del Guadiana en plenas Vegas bajas y que tiene su desembocadura a la altura del pueblo de Talavera la Real.

\subsection{Los dólmenes de la cabecera del río Rivillas}

En el nacimiento de la cuenca del Rivillas se encuentran los dólmenes de Revellado 1, 2 y 3 (Fig. 6). Destaca el Revellado 1, dolmen de corredor largo excavado por P. Bueno en los ańos 80 y en el que se ha constatado el uso de piedras de caliza blanca junto al predominante granito (Bueno, 2002: 58 y fig. 15). Se asienta sobre un sustrato de granitos alcalinos, cuarzosienitas alcalinas, y está ubicado en llano junto al nacimiento del citado río. Los otros dos, aunque se han considerado de buen tamańo (Bueno, 2002: 58), parecen más pequeños pese a que es cierto que están bastante arruinados en superficie. Precisamente uno de ellos, el Revellado 2, fue excavado por el conde de Valencia de don Juan a fines del s. XIX y de sus trabajos se divulgó la presencia de huesos humanos, hachas y cerámicas (Rada y Vilanova, 1890: 505; Mélida, 1925: 44). Ambos, a diferencia del Revellado 1, no están en terreno granítico, sino de calizas y dolomías, en un área de contacto con pizarras que tiene a una distancia de $250 \mathrm{~m}$ al o una banda del denominado granito de Valverde, compuesto por sienitas alcalinas y granófiros. Se localizan junto al arroyo de Valdesevilla, que vierte en el Rivillas.

$\mathrm{Al}$ igual que el grupo anterior, la intervisibilidad y el área de influencia teóricas proporcionan un territorio muy similar, bien individualizado tanto en relación con el cercano grupo del Romo y la cuenca del río Limonetes, como hacia el Noreste por donde tiene salida el curso del río Rivillas por el denominado cordel de Valdesevilla (Fig. 6).

Se trata pues de una pequeña adición de tres dólmenes, uno de ellos más grande que los otros, en tierras predominantemente llanas, dentro de un área geográfica donde nacen cursos de agua que se integran en la cuenca del río Rivillas, que discurre 


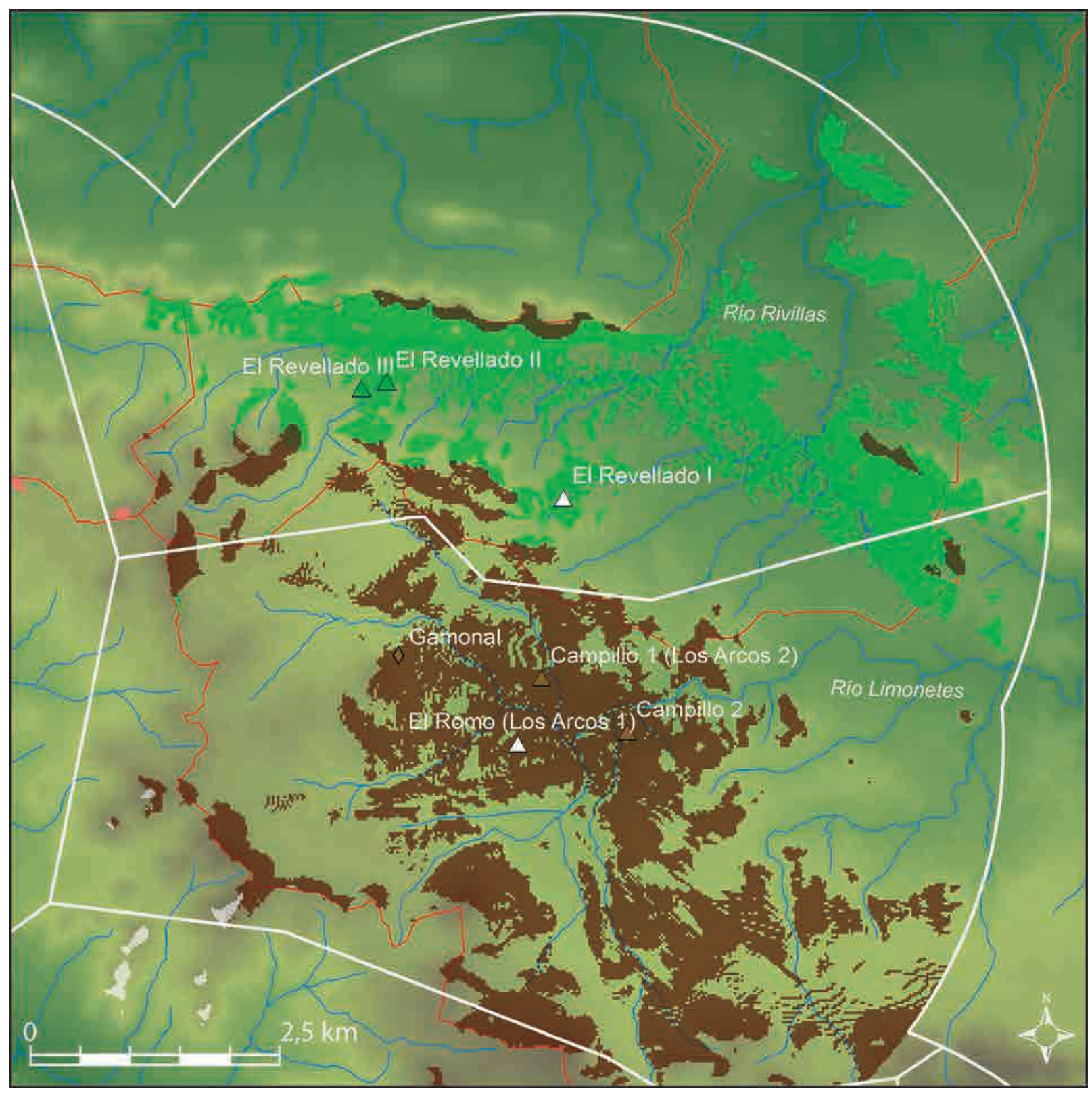

FIG. 6. Territorialidad hipotética de los grupos de las cabeceras de los ríos Limonetes y Rivillas.

hacia el $\mathrm{N}$ en dirección a los llanos del Guadiana para desembocar a la altura de Badajoz.

\subsection{Los dólmenes de la Dehesa de Monteporrino}

El más meridional es el grupo de la Dehesa de Monteporrino, junto a Salvaleón (Fig. 3). Es el que se ha reconocido más recientemente ya que, aunque existían referencias a un dolmen en Monteporrino, no ha sido hasta hace pocos ańos cuando se han dado a conocer 14 estructuras megalíticas además de dos menhires seguros, otros probables y algunas cistas (Sanjuán, 2006). Las estructuras megalíticas se sitúan en una zona amesetada que supera los $600 \mathrm{~m}$ de altitud, entre dos arroyos: el arroyo del Campo, que es tributario del río Ardila, 
y el de las Contiendas, afluente del río Alcarrache (Fig. 7). En ella se encuentra la divisoria de aguas entre las cuencas del Ardila y del Alcarrache, cuenca la de este río que precisamente nace aquí. Además, esta confluencia constituye el punto de unión entre las comarcas de Jerez de los Caballeros y Tierra de Barros, de manera que se trata de un punto de enlace importante entre las serranías del Sur y las tierras más llanas de la citada comarca de Barros y también de la penillanura de las de Barcarrota-Olivenza (Fig. 3). Los ríos y las sierras circundantes determinan una compleja red viaria que en este punto se articula en dos ejes fundamentales: el cordel del Alcarrache y la Cañada Real de Salvaleón por Monteporrino o Cañada Real de Madrid, salida natural a las citadas comarcas de Tierra de Barros y Olivenza hacia la de Jerez de los Caballeros.

Once de las estructuras están sobre un sustrato cuarcito-pizarroso con afloramientos de esquistos y grauvacas, que es donde se encuentra la divisoria entre las cuencas del Ardila y Alcarrache. Se disponen de un modo casi longitudinal, de SE a NO, a lo largo de 3 $\mathrm{km}$ en la vertiente que da al arroyo de las Contiendas, con el dolmen más septentrional -Monteporrino 1algo separado del resto, pero sobre el punto exacto de confluencia de las cuencas hidrológicas citadas. Los otros tres están más al E, dentro de la cuenca del Ardila, en la zona de contacto entre el sustrato cuarcito pizarroso y otro de granitos biotíticos, sobre suelos poco profundos de explotación tradicionalmente mixta, como en toda esta zona hoy adehesada. No obstante, apenas distan $1 \mathrm{~km}$ en línea recta de la parte central del otro grupo (Fig. 7). Considerando otras variables más allá de la geológica, hidrológica, edafológica y topográfica, como la visibilidad y las áreas de influencia teóricas, se confirma que los dólmenes de Monteporrino constituyen un grupo de particular articulación y territorialidad, puesto que resulta un tanto especial por la personal disposición casi en línea, pero no alineada, de las once estructuras que están sobre la meseta muy cerca de la caída al arroyo de las Contiendas. Recuerda, con sus especificidades, a algunos de los alineamientos de mamoas en las divisorias de aguas entre zonas geográficas distintas del interior de Galicia (Gómez Vila, 2005: 420). Pero aquí quizás la explicación de esa disposición lineal en $3 \mathrm{~km}$ pueda estar en el interés por señalizar y monumentalizar de una manera especial, y con una destacada dimensión simbólica, la apropiación específica de este punto de contacto intercomarcal, con Monteporrino 1 en el punto exacto de unión de las dos cuencas. Más arriesgado es proponer una explicación para el grupo más oriental de las tres estructuras separadas de la línea de concentración, aunque probablemente esté más en clave de articulación social diferencial sobre este espacio concreto.

El estado de conservación de los dólmenes de Monteporrino es bastante malo, hay muchas estructuras que están prácticamente desmanteladas, otras muy desfiguradas o removidas y un gran número de ortostatos están desplazados y reutilizados en construcciones parásitas. Ese estado dificulta su valoración y las posibilidades de estudio de cara a una clara definición y seriación de las mismas. Sólo dos de las estructuras pueden definirse desde el punto de vista arquitectónico: Monteporrino 1 y 2, denominada también Caballería Nueva y que corresponde al n. ${ }^{\circ} 13$ del inventario de Sanjuán (2006). Son las dos únicas en las que se han hecho excavaciones hasta ahora ${ }^{5}$ (Carrasco, 2006). Del resto es muy difícil apuntar a qué tipo arquitectónico pudieron pertenecer. Algunas tienen huellas de la existencia de corredor, otras no. En los tamańos por su parte también se contemplan diferencias, pero con muchas imprecisiones.

Las excavaciones en las estructuras Monteporrino I y Monteporrino 2 mostraron que ambas estaban violadas y muy alteradas, hasta el punto de que en la segunda de ellas no se encontró ningún elemento mueble. La primera está justo en el límite de aguas entre las cuencas del Alcarrache y Ardila como ya hemos apuntado y la cubría un túmulo desfigurado de más de $20 \mathrm{~m}$ de diámetro reconocible. Contenía una cámara de cinco ortostatos con un pequeño nicho, formado por una sola pieza de esquisto retranqueada, y un corredor corto. La cubrición parece que fue a base de grandes losas de pizarra apoyadas sobre los ortostatos y sobre pequeños muretes de nivelación (Carrasco, 2006). Un rasgo constructivo éste que también se aprecia en dólmenes de la zona de Barcarrota como el de la Mezquita 1 y otros (Bueno, 1987: 75). En total tenía doce ortostatos, diez de esquisto, uno de pizarra y otro de granito. Presenta así un módulo que no

5 Carrasco, M. J. (2006): Sepulcros megaliticos. Salvaleón (Badajoz). Badajoz: Junta de Extremadura. Folleto divulgativo. 


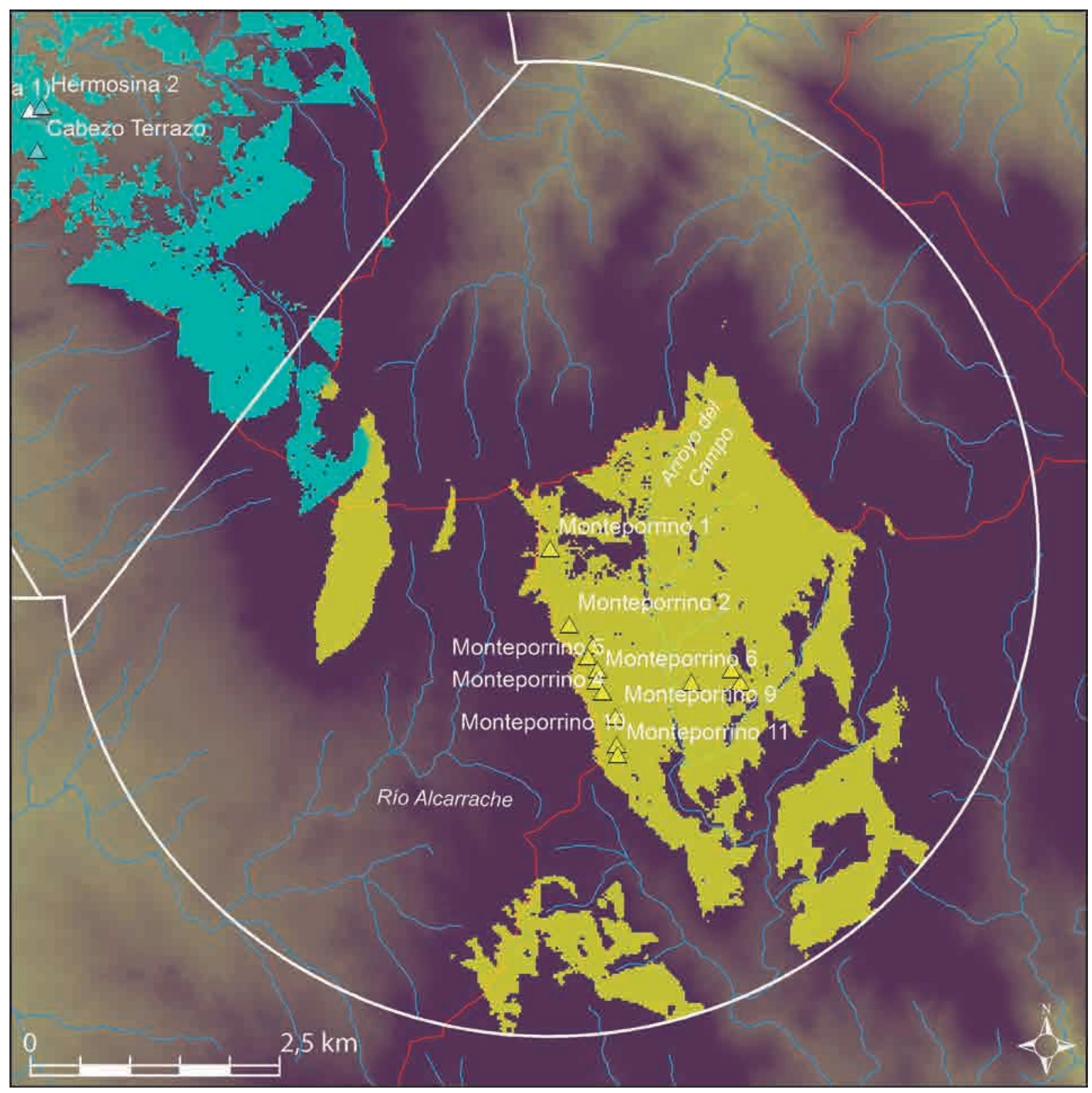

FIG. 7. Territorialidad hipotética del grupo de Monteporrino.

es el más habitual en la zona, pero no desconocido en el área alentejano-extremeña. Proporcionó pocos elementos de ajuar, entre los que destaca un vaso campaniforme liso incompleto. El de Monteporrino 2 pertenece al grupo de tres separados del alineamiento de los once cuyo límite septentrional lo marca Monteporrino 1. Se levantó sobre un afloramiento granítico algo destacado del entorno y se trata de un sepulcro cerrado de planta trapezoidal de 3,80 m de longitud, que estaba completamente vacío. En él se habían utilizado dos piedras de esquisto. Del túmulo sí quedaban trazos reconocibles en un diámetro de $17 \mathrm{~m}$ y en las cercanías están las otras dos estructuras prácticamente desmontadas, una de las cuales al menos fue de mayores dimensiones que ésta. 
La valoración que puede hacerse de este grupo de Monteporrino es todavía muy parcial, pese a lo cual puede afirmarse que se integran en él arquitecturas distintas tanto en tipología como en tamaño, dentro de las cuales las documentadas en Monteporrino 1 y 2 no corresponden precisamente a las más características del amplio foco alentejano-extremeño, aunque no son tampoco desconocidas. Pero en la esfera territorial hay al menos una serie de cuestiones que parecen claras: primero su situación en el punto de contacto entre dos cuencas y que de dicha zona de contacto nace la cabecera del Alcarrache, con lo cual coincide con la ubicación en el nacimiento de cuencas que presentan también los grupos del Milano, Mezquita 1-Cañada de la Murta, El Romo y el Revellado. En segundo lugar, cómo ese punto de contacto hidrológico tiene un alto interés estratégico al ser un espacio de confluencia y tránsito intercomarcal, lugar de encuentro entre ecosistemas distintos podríamos decir, que le dota de un especial significado. Estos factores geofísicos debieron ser los más determinantes y explicarían en buena medida, como hemos apuntado, la singular disposición casi longitudinal de las once de las estructuras en ese punto de contacto desde distintas unidades geográficas, a una altura siempre superior a los $610 \mathrm{~m}$. El especial significado del lugar se ve reforzado por la continuidad funeraria que parece marcar la presencia en la misma finca de cistas.

\subsection{Tholoi y poblados}

En el área de Barcarrota se ha señalado la existencia al menos de dos posibles tholoi: la Mata y la Pestaña (Fig. 3), ambos excavados sin criterios científicos de ninguna clase y por tanto mal conocidos, pese a que los materiales conservados procedentes del segundo son muy claramente calcolíticos. La Mata se encuentra en la margen derecha del río Olivenza, en un terreno granítico a una cota de 330 $\mathrm{m}$. Al parecer fue excavado en su día por el destacado regionalista extremeño José López Prudencio sin que hayan trascendido más noticias al respecto (Bueno, 2002: 60). En la otra margen estaba el sitio de la Pestaña, en la finca los Fresnos (Villanueva, 1894), dentro de una zona de confluencia entre pizarras, cuarcitas, calizas y granitos. La Pestaña es otro posible tholos, cuyos materiales arqueológicos corresponden a un Calcolítico avanzado que ofrece notables diferencias con los elementos más característicos de los ajuares dolménicos de la zona (Enríquez y Palomo, 2014). La integración en el paisaje de ambos tholoi no es muy diferente de la que ofrecen otros conocidos y no muy lejanos como los de Colada de Montenuevo en Olivenza (Schubart, 1973) y Granja del Toniñuelo en la comarca de Jerez de los Caballeros (Carrasco, 1991). Se encuentran así apartados de los grupos dolménicos.

También, en la franja más septentrional se han localizado una serie de poblados calcolíticos con patrones muy similares: ubicación en altos de carácter estratégico con control visual sobre los cursos de agua, sobre todo en la cuenca del Olivenza, y cercanía a los teóricos mejores suelos para su explotación: la Corona, Castillo de Valverde de Leganés, La Pina, San Lorenzo, San Jorge, Pedra Furada en la Sierra de Alor, etc. Respecto a ellos, se ha valorado su situación y emplazamiento como el límite noroccidental del territorio de control e influencia directa de Tierra de Barros, que capitaliza el yacimiento de la Pijotilla (Hurtado y Mondéjar, 2009).

La integración territorial de poblados calcolíticos y tholoi presenta ya otras características muy diferentes a la de los dólmenes, con una articulación estratégica de dominio y control en torno a toda la ribera del río Olivenza (Fig. 3).

\section{Caracterización territorial del fenómeno megalítico del área de Barcarrota}

El intento de definir un modelo de identidad para el paisaje megalítico generado en esta área geográfica presenta distintos niveles de dificultad. Por un lado, hay que resaltar que se trata de una zona muy antropizada, donde sabemos de rebuscas y hallazgos antiguos en diversos dólmenes (Mélida, 1914, 1924 y 1925; De los Santos, 1939), de excavaciones inéditas realizadas sin criterios claros (Mélida, 1924 y 1925; Bueno, 2002: 60), de estructuras desmanteladas (Villanueva, 1894) y de más modernas incidencias, sobre todo, como consecuencia de labores agrícolas y visitas incontroladas. De otra parte, están las limitaciones de un registro arqueológico poco abundante y con muchas imprecisiones $y$, especialmente, la complejidad y dificultad propias en la percepción de un paisaje que responde 
a sus propios códigos y contextos socioculturales (Criado y Villoch, 1998: 64-65). Pese a todo ello, hay ciertas pautas a considerar (Fig. 8).

\subsection{Dólmenes e hidrología}

Desde la dehesa de Monteporrino hasta el inicio de los llanos de Olivenza hay un factor que se repite, la presencia de agrupaciones de dólmenes en el nacimiento de las cuencas de los cursos de agua más importantes que los articulan en una red con distintas direcciones: Alcarrache, Olivenza, Limonetes y Rivillas. La estructuración de esas agrupaciones es solo ligeramente variable, grupos de 3 o 4 dólmenes que conforman la unidad territorial, dentro de la cual hay al menos uno de ellos que es más grande y monumental. Por otro lado, esta presencia de grupos pequeños en las cabeceras de los ríos plantea el valor o papel simbólico que pudieron jugar las aguas de los cursos nacientes, dentro de esa dimensión del paisaje megalítico. La importancia o interés de este elemento se ve reforzado por el hecho de que junto a la localización de la mayoría de los dólmenes agrupados hay también fuentes y veneros: Milano, Revellado 1 y 2, Romo, etc. No se trata por tanto de una relación espacial genérica con el agua, como en unión a otros factores se puede señalar para los dólmenes aparentemente aislados y los tholo $i$, sino estrecha y centrada en su carácter naciente. Esta asociación se pierde ya al entrar en los llanos de Olivenza al n y también en la cuenca del Ardila al s, donde encontramos como los dólmenes se disponen preferentemente en áreas de valle de acuerdo a otros criterios (Prada y Cerrillo Cuenca, 1996-2003: 53 y ss.).

No es un caso excepcional, pues la presencia de grupos de dólmenes en el nacimiento de cursos de agua de la red secundaria se aprecia también en la cartografía de los sepulcros megalíticos de la sierra de Aboboreira, en la cuenca del Duero, especialmente a partir de la fase 2 (Oliveira Jorge, 1991: 156 y fig. 16).

El caso del grupo de Monteporrino ofrece particularidades como hemos destacado, tal vez debidas a la especial significación que adquirió este espacio de confluencia intercomarcal de cara a la apropiación real, simbólica y funeraria de este lugar.

Al margen de esos grupos o asociaciones, los dólmenes de la Lapilla y la Lapita, y tal vez los de
Montes Calderón y la Reyerta, exponen como fuera del nacimiento de las cuencas la estructura del paisaje megalítico cambia. Sin tener su localización en los puntos del paisaje de donde parten los ríos y arroyos principales, están discretamente dispuestos en ambas márgenes de la ribera del Olivenza sin formar asociaciones ni agregaciones, dispersos frente a la concentración y agrupamiento de los situados en las cabeceras.

\subsection{Dólmenes y caminos y vías de comunicación}

El caso de los caminos y veredas aparece como otro factor a considerar. Una especial relevancia adquiere el caso de Monteporrino, no solo por la presencia de la Cañada Real Soriana Occidental y el cordel del Alcarrache desde Monteporrino, que parte de allí, sino de una manera especial por tratarse de un espacio natural de encuentro intercomarcal. De otra parte, en la franja septentrional de la zona, entre los términos de Valverde de Leganés y Olivenza, surge la vía pecuaria de Sancha Brava, que es un ramal de la Cañada Real Soriana Occidental que cruza el Guadiana a la altura de Badajoz por el vado del Moro. Pero esas grandes vías del pastoreo histórico parten de los rebordes norte y sur, es decir, que no atraviesan la zona. Por ello el tránsito por otros caminos locales tiene un protagonismo viario importante, más allá incluso del ámbito interno a tenor del carácter de la zona como área de transición entre comarcas diferentes. Es el caso del camino que discurre por la sierra de los Gavilanes desde Salvaleón a Olivenza, donde se sitúa el subgrupo de Cañada de la Murta; el de Salvaleón a Barcarrota, donde está el de Mezquita 1, y el llamado cordel de la antigua aldea de Valdesevilla, que parte hacia los llanos del Guadiana por el Revellado.

La relación con los caminos históricos reconocidos es así importante, pero más que con las grandes rutas es con el tránsito que marcan las vías de comunicación internas, de enlace, en especial aquellas que siguen el trazado de los cursos de agua. De este modo, no es una relación como la señalada para los dólmenes de Almadén de la Plata con respecto a las rutas medievales de trashumancia por Sierra Morena (Murrieta-Flores et al., 2011) o para zonas de la provincia de Lugo en el interior de Galicia (Gómez Vila, 2005). 


\subsection{Dólmenes y visibilidad, topografía y áreas de influencia}

La visibilidad, por su parte, resulta también del máximo interés, primero porque los dólmenes de cada grupo son teóricamente intervisibles, pero no conectan con la de los grupos vecinos ni siquiera con aquellos que, fuera de los inicios de cuencas, se encuentra aislados. Pero también la visibilidad proporciona otra característica relevante pues, siendo uno de los aspectos esenciales para la consideración de los dólmenes como marcadores de paisaje, la situación de los mismos es muy discreta en su integración. No tienen una visibilidad fácil salvo en las inmediaciones, sobre todo los mayores y más monumentales, los cuales entran dentro de la categoría visual que se ha definido como puntual, mientras los grupos cuentan con una visibilidad sectorial (Criado y Vaquero, 1993), tanto en la percepción de los mismos como en los campos que desde ellos se abren.

La visibilidad y percepción en relación con la variante topográfica permiten destacar como ésta no es dominante aquí, de modo que se presenta de manera muy distinta a la de otras áreas megalíticas donde sí que se disponen los dólmenes en collados y puntos altos de las sierras, como ocurre en la zona almeriense de Tabernas, por citar solo un ejemplo (Cámara, 2009). Tampoco el emplazamiento de los menhires resulta destacado, aunque se hallan actualmente algo desplazados. Por otra parte, no se ha reconocido ningún elemento natural o hito geográfico destacado, salvo el agua naciente, que pudiera haber significado una referencia paisajística o simbólica, lo cual no implica que no hubieran existido en claves distintas a las de percepciones topográficas y paisajísticas actuales.

Las áreas de influencia teórica presentan una sorprendente sintonía con los campos visuales y la topografía, de modo que sirven para reforzar las asociaciones en grupos expuestas y la nítida separación entre unos y otros. También los alcances de la visibilidad y la percepción de los grupos y de los elementos arquitectónicos integrantes de los mismos, que apuntan en dirección a un territorio particular para los dólmenes que no se presentan en agrupaciones. Pocas aportaciones ha proporcionado la consideración de la insolación anual general, muy en relación con la topografía no dominante de los emplazamientos y su visibilidad y percepción.

\subsection{Dólmenes y geología, suelos y potencial explotación económica}

La geología no parece haber jugado un papel determinante en la organización de estos espacios dolménicos, con algunos casos expresivos como los de la Lapilla, Revellado 2 y 3, para cuyas ubicaciones no se eligieron afloramientos graníticos cercanos, sino que primaron otros criterios menos pragmáticos y por tanto seguramente más simbólicos y culturales como a veces se ha propuesto (Criado y Villoch, 2000). En relación con la litología cabe apuntar que al menos en el Milano, Mezquita 1, Revellado 1, Monteporrino 1 y Monteporrino 2 se tiene constatación de la utilización de otras clases de piedra ajenas a las inmediaciones, en principio de la propia zona, como dioritas en el primero, pizarras y cuarzos en el segundo, calizas en el tercero, granitos en el cuarto y esquisto en Monteporrino 2. Muy posiblemente la limpieza de otros dólmenes aportaría otros ejemplos del uso de diversas materias primas en una misma estructura, un uso de piedras de distintas clases y procedencia que se viene constatando como nada inusual y cuyo carácter simbólico no se puede descartar, a tenor del esfuerzo que implica a veces su traslado y, sobre todo, la diferenciación visible que con ello se obtiene.

Igual ocurre con las teóricas áreas de mayor capacidad productiva de la tierra, donde no se concentra la presencia de dólmenes, aunque en las inmediaciones de todos los grupos hay espacios fértiles con agua abundante, tradicionalmente aprovechados para cereales y huerta en sintonía con los escasos datos arqueobotánicos que permiten apuntar la existencia de un paisaje abierto y transformado en parte por las actividades agropecuarias. Distinto es el caso de las ubicaciones de los poblados calcolíticos, que sí que parecen guardar una mayor relación con las áreas teóricamente más fértiles.

\subsection{Dólmenes, arquitectura y ajuares}

El registro arqueológico disponible hace muy limitada la consideración de estas variables de estudio. Las características arquitectónicas de los dólmenes de área geográfica de Barcarrota son muy similares a las que presentan otras zonas alentejano-extremeñas. Se trata de estructuras con siete ortostatos en la 
cámara, a veces con uno recortado junto a la piedra de cabecera (Bueno, 1987: 78), casi todos con restos de corredor, pero con diferentes diámetros en la cámara y en la longitud del corredor. Algunos se salen de ese patrón o modelo habitual, como los casos de Monteporrino 1 y 2 que se han comentado, que remarcan la presencia de otras variantes arquitectónicas que convivieron en tiempo y espacio. Pocas son las evidencias de la presencia de grabados, pero sobre la cubierta del Revellado 1 y 2 y en la Lapita se han localizado cazoletas (Bueno y Balbín, 2003: 415), que pese a ser el motivo más simple y abundante presente en distintas arquitecturas, no es en este caso sino un indicio de que podrían encontrarse más manifestaciones de esta clase con una limpieza de ortostatos. Por otro lado, sabido es que, dentro de las creencias y símbolos asociados a las manifestaciones megalíticas, se ha destacado la importancia que tuvo la orientación de los sepulcros y ciertas implicaciones que la misma pudo conllevar (García Sanjuán, 2009: 26). En el caso de estos dólmenes de Barcarrota no se han constatado anomalías en cuanto a una orientación al orto solar. Hoskin y Sauch (1999: fig. 6 y tab. 2) estudiaron la orientación de nueve de ellos, que presentaron un intervalo entre $86^{\circ}$ y $121^{\circ}$.

Respecto a los objetos muebles más característicos, se trata de cerámicas casi siempre lisas, pulimentados en anfibolitas sobre todo, puntas de flecha en diversos materiales, trapecios, se conocen algunas cuentas de collar y destacan los ídolos placa, a los que ya se aludió a propósito de los procedentes del Milano. Resultan globalmente muy característicos dentro de una indefinición contextual ya que excavaciones modernas solo se han efectuado en el Revellado 1, el Milano y Monteporrino 1 y 2 y es preciso tener presentes los conocidos problemas de relación lineal entre arquitectura y ajuar (Rocha, 2009/2010: 80). La existencia en un vaso cerámico depositado en el suelo con pólenes casi exclusivos de la flor del nazareno bien pudiera corresponder a una ofrenda floral, muy pocas veces documentada.

\section{Conclusiones}

La implantación megalítica en el área de Barcarrota responde a un modelo de integración territorial que podríamos definir como propio de áreas de transición geográfica en la cabecera de cuencas fluviales secundarias. Sus estructuras ocupan y monumentalizan un espacio interior que conecta los llanos fluviales del Guadiana y las primeras estribaciones de Sierra Morena, y lo hace fundamentalmente a través del nacimiento de cuencas hidrográficas secundarias. Pero, al respecto, hay que volver a destacar que este espacio de conexión no es la arteria principal de unión entre las Vegas del Guadiana y las estribaciones de Sierra Morena, papel que corresponde a las llanuras de Tierra de Barros y a la ribera del propio Guadiana, sino que se trata de un área de transición entre comarcas mejor definidas geográficamente tanto al $\mathrm{N}$ como al s, E y o.

Ese modelo de implantación viene bien definido por la concentración de pequeños grupos en torno al naciente de los ríos, la cual se rompe aguas abajo donde ya desaparecen las agrupaciones jerárquicas con que se monumentalizaron esos nacientes. Por ello, siendo el emplazamiento el primer recurso en base al cual se construye el espacio megalítico (Criado y Vaquero, 1993: 211), la apropiación física y simbólica del nacimiento de las cuencas es el rasgo más sobresaliente. El agua naciente adquiere así un valor simbólico muy destacado, en torno al que se advierte la concentración preferente de las estructuras dolménicas. En este sentido, el grupo del Milano expresa bien el modelo de agrupación, con un dolmen más grande y monumental discretamente ubicado y en las cercanías, a una distancia no superior a $1900 \mathrm{~m}$, otros menores más facialmente perceptibles. Todo ello en un espacio donde además de la hidrografía, la interrelación de otros factores como son la visibilidad, los territorios teóricos de influencia o la topografía define verdaderas unidades (Fig. 8).

Su implantación en un área geográfica de transición contempla un valor viario que se imbrica en un tránsito sobre todo local e intercomarcal. Ninguno de los grandes caminos históricos la atraviesa, pero sí que hay otras vías y caminos de enlace. Un caso especial es el del grupo de dólmenes de Monteporrino, en un terreno donde conectan la Cañada Real Soriana Occidental y el cordel del Alcarrache, cuya singularidad ha sido destacada también en aquello que se refiere a la especial disposición de los dólmenes sobre el terreno, en la divisoria de aguas entre las cuencas del Ardila y Alcarrache, que nace allí. 


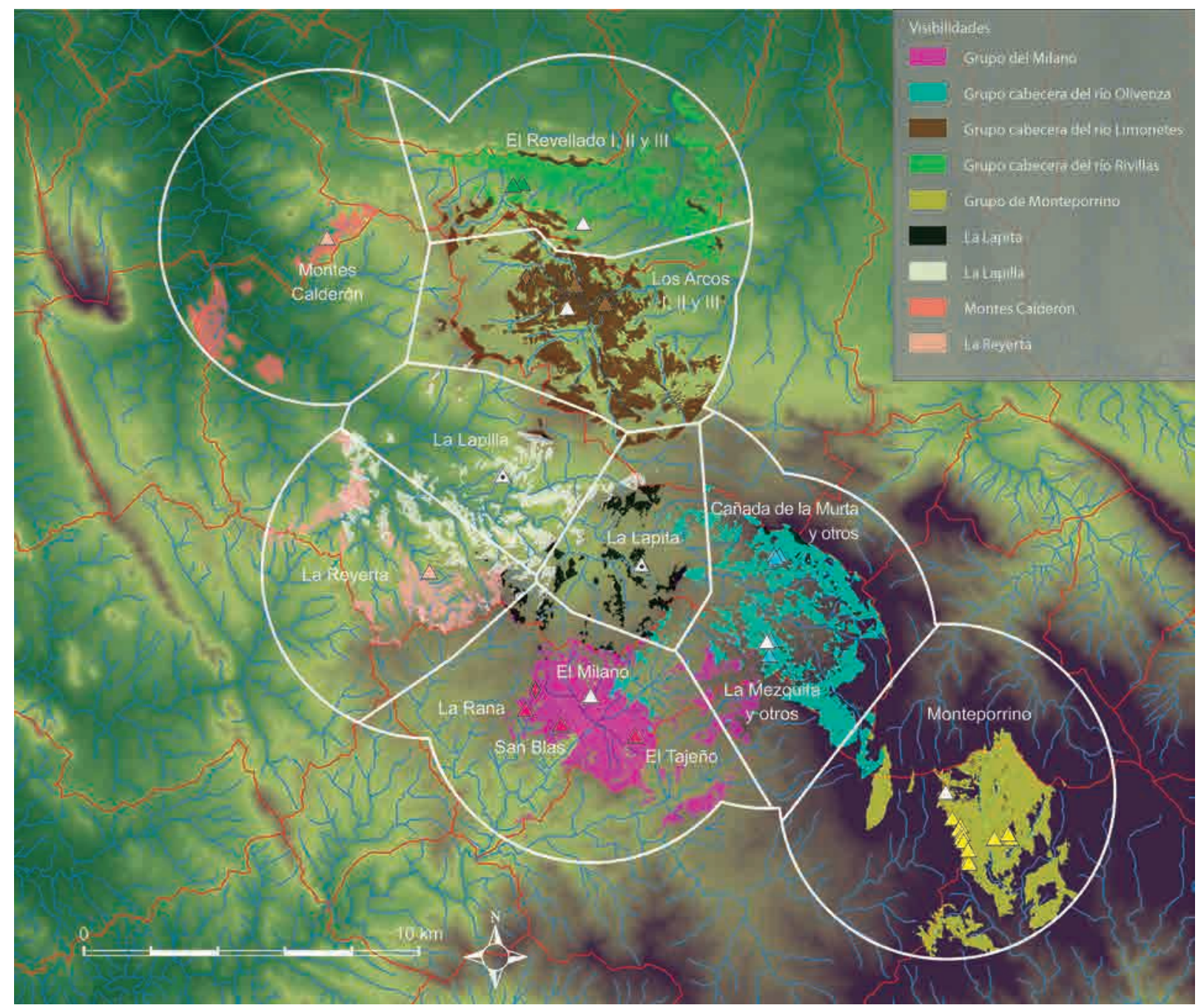

Fig. 8. Articulación territorial de los dólmenes del área de Barcarrota (Badajoz).

De otras variables territoriales cabe destacar que es un área geográfica donde los recursos económicos susceptibles de explotación no debieron tener especial relevancia, más allá de unos aprovechamientos agropecuarios adaptados a la relativa potencialidad de estos entornos, mostrando un paisaje abierto y de matorral sustitutivo de quercíneas perennifolias y caducifolias y un dosel ripario ajustado a los cursos fluviales. De esta forma, parece que las mejores tierras, situadas siempre en los márgenes de nuestro ámbito de estudio, no concentraban agrupaciones dolménicas y, por tanto, no fueron un factor relevante en la elección para la monumentalización de estos espacios.
Obviamente ese paisaje que hemos intentado caracterizar de una manera global puede ser el resultado de adiciones, de reconducción de fenómenos de continuidad y de creación de tradiciones. En este sentido, carecemos de dataciones para establecer una secuencia y por tanto no podemos concretar sincronías o diacronías en la zona. Pero desde el punto de vista de una aproximación cronológica amplia, ese paisaje parece corresponder al momento de implantación y desarrollo central del fenómeno megalítico. Si tomamos como referencia las dataciones de áreas vecinas el fenómeno estaría bien consolidado a medidos del IV milenio a. C. Más tarde, una vez establecido y desarrollado, bien 
en un corto periodo de tiempo o de una manera temporalmente escalonada, ese paisaje estructurado se transformó. Muy posiblemente con ciertas reutilizaciones, como puede ser que exponga el campaniforme liso de Monteporrino 1, pero sobre todo y de manera definitiva como consecuencia de un cambio de territorialidad importante. Ese cambio viene expresado en el territorio por nuevas referencias: los poblados calcolíticos localizados en altos estratégicos que controlan el pasillo del Olivenza, ubicados cerca de las mejores tierras, y las nuevas estructuras funerarias como los posibles tholoi de la Mata y la Pestaña.

Poblados y tholoi marcan un reordenamiento del espacio con nuevos ejes de referencia que se centran en la cuenca del río Olivenza. Es decir, un paisaje cultural diferente, propio de los sistemas de control socioeconómico y territorial del Calcolítico del so, donde las tierras fértiles y la presencia de otros recursos del medio físico concentraron los hitos poblacionales y simbólicos del paisaje cultural, que en el caso del área de Barcarrota acusa la influencia de elementos ideológicos y sociales de los grandes poblados del Guadiana extremeño como La Pijotilla y San Blas (Enríquez y Palomo, 2014).

\section{Bibliografía}

Allué, E. (2000): "Pollen and charcoal analices from archaeological sites from the Alto Ribatejo (Portugal)". En Cruz, A. R. y Oosterbeek, L.: Territorios, Mobilidade e Povoamento no Alto Ribatejo. Industrias e Ambientes. Arkeos, 9. Perspectivas em Diálogo, Tomar, pp. 37-57.

Bueno, P. (1987): "Megalitismo en Extremadura. Estado de la cuestión”. En El Megalitismo en la Peninsula Ibérica. Madrid: Ministerio de Cultura, pp. 73-85.

Bueno, P. (1992): "Les plaques décorées alentéjaines : aproche de leur étude et analyse", L'Anthropologie, 96 (2-3), pp. 573-604.

Bueno, P. (2002): "El espacio de la muerte en los grupos neolíticos y calcolíticos de la Extremadura española: las arquitecturas megalíticas". En Extremadura Arqueológica VIII. El Megalitismo en Extremadura. Mérida, pp. 35-80.

Bueno, P. y Balbín, R. DE (2003): “Grafías y territorios megalíticos en Extremadura”. En Gonçalves, V. S. (ed.): Muita gente, poucas antas. Origens, espaços e contextos do megalitismo (Actas II Coloquio Internacional sobre Megalitismo). Lisboa, pp. 407-448.
Cámara, J. A. (2009): “Almería”. En García Sanjuán, L. y Ruiz González, B. (coords.): Las Grandes Piedras de la Prehistoria. Sitios y Paisajes Megaliticos de Andalucia. Antequera: Junta de Andalucía, pp. 32-53.

Carrasco, M. J. (1991): "Avance al estudio del sepulcro megalítico de la Granja del Toniñuelo (Jerez de los Caballeros, Badajoz)". En Extremadura Arqueológica II, pp. 113-129.

Criado, F. y Vaquero, J. (1993): "Monumentos, nudos en el pañuelo. Megalitos, nudos en el espacio. Análisis del emplazamiento de los monumentos tumulares gallegos", Espacio, Tiempo y Forma. Serie I. Prehistoria y Arqueología, 6, pp. 205-248.

Criado, F. y Villoch, V. (1998): "La monumentalización del paisaje: percepción y sentido original en el megalitismo de la sierra de Barbanza (Galicia)", Trabajos de Prehistoria, 55 (1), pp. 63-80. http://dx.doi.org/10.3989/tp.1998.v55.i1.317

Criado, F. y Villoch, V. (2000): "Monumentalizing landscape: from present perception to he past meaning of Galician Megalithism (north-west Iberian Peninsula)", European Journal of Archaeology, 3 (2), pp. 188-216. http://dx.doi.org/10.1179/eja.2000.3.2.188

De los Santos, S. (1939): "Expansión del arte eneolítico portugués en Extremadura. Hallazgos en Barcarrota”, Revista de Estudios Extremeños, XIII (3), pp. 189-202.

Devesa, J. A. (1995): Vegetación y flora de Extremadura. Badajoz: Universitas editorial.

Duque, D. M. (2002): “Aproximación a la evolución del paisaje vegetal neolítico de la cuenca del río Sever a partir de los datos antracológicos preliminares de varios monumentos megalíticos", Ibn Marúan, 12, pp. 199-230.

Duque, D. M. (2005a): "Resultados antracológicos de los yacimientos de la Coudelaria de Alter do Chao y su integración en las secuencias paleoecológicas y paleoambientales de la Prehistoria Reciente del Suroeste Peninsular”, Revista Portuguesa de Arqueologia, 8 (1), pp. 21-42.

Duque, D. M. (2005b): "Aproximación al paisaje vegetal de los grupos megalíticos del río Sever a partir de los datos antracológicos de varios dólmenes". En Actas III Congreso del Neolitico en la Península Ibérica. Monografías del IIIPC, 1. Santander, pp. 125-134.

Duque, D. M. (2006): "El medio vegetal de la Coudelaria de Alter do Chao a partir de los resultados antracológicos”. En Oliveira, J. DE (coord.): Patrimonónio Arqueológico da Coudelaria de Alter e as primeiras comunidades agropastoris. Lisboa: Edições Colibri/Univ. Évora, pp. 242-256.

Enríquez, J. J. y PAlomo, S. (2014): "Materiales inéditos del Calcolítico procedentes de la Pestaña (Badajoz)”, Spal, 23, pp. 121-136. http://dx.doi.org/10.12795/spal.2014.i23.06

Fernández Caballero, A. (1999): Tras las huellas de un pueblo (Valverde de Leganés: su Historia). Badajoz. 
Figueiral, I. (1998): “O Abrigo da Pena d'Água (Torres Novas): a contribução da antracologia”, Revista Portuguesa de Arqueologia, 1 (2), pp. 73-79.

García SanjuÁn, L. (2009): "Introducción a los sitios y paisajes megalíticos de Andalucía”. En GARCía SANJuÁN, L. y BARTOLOMÉ, B. (eds.): Las Grandes Piedras de la Prehistoria. Sitios y Paisajes Megalíticos de Andalucía. Antequera: Junta de Andalucía, pp. 12-32.

Gómez Vila, J. (2005): "Caminos y túmulos. Aproximación al estudio de los caminos megalíticos en el noroeste peninsular". En Arias, P.; Ontañón, R. y GarcíaMoncó, C. (eds.): Actas III Congreso del Neolitico en la Peninsula Ibérica (Santander, 2003). Santander: Univ. de Cantabria, pp. 405-412.

Hoskin, M. y SaUCH, C. (1999): "Studies in Iberian Archaeoastronomy: (6) Orientations of Megalithic Tombs of Badajoz and Neighbouring Portugal", Archaeoastronomy, 24, pp. 35-40. http://dx.doi.org/10.1177/002182869903002403

Hurtado, V. y Mondéjar, P. (2009): “Prospecciones en Tierra de Barros (Badajoz). Los asentamientos del III milenio”. En Cruz Auñón, R. y Ferrer, E. (coords.): Estudios de Prehistoria y Arqueología en homenaje a Pilar Acosta Martínez. Sevilla: Universidad de Sevilla, pp. 187-206

Leisner, G y V. (1959): Die Megalithgräber der Iberischen Halbinsel. Der Westen. Madrider Forschungen, Band 1. Berlín: de Gruyter.

López García, P. (1994): “Análisis polínicos”. Apéndice a Bueno, P.: "La necrópolis de Santiago de Alcántara (Cáceres). Una hipótesis de interpretación para los sepulcros de pequeño tamaño del megalitismo occidental", Boletín del Seminario de Estudios de Arte y Arqueología, LX, pp. 97-100.

López Romero, E. (2007): "Factores visuales de localización de los monumentos megalíticos de la Cuenca del Sever (Portugal-España)", Trabajos de Prehistoria, 64 (2), pp. 73-93.

MélidA, J. R. (1914): “Arqueología dolménica ibérica. Dólmenes de la provincia de Badajoz", Revista de Archivos, Bibliotecas y Museos, 28, pp. 1-24.

Mélida, J. R. (1924): "Grupo de dólmenes en término de Barcarrota (provincia de Badajoz)", Sociedad Española de Antropología, Etnología y Prehistoria, III, pp. 131-137.
MélidA, J. R. (1925): Catálogo Monumental de Mérida. Provincia de Badajoz. Tomo I. Madrid: Ministerio de Instrucción Pública y Bellas Artes.

Muelas, A. y Soubrier, J. (1977): Mapa Geológico de España 1:50.000, hoja 828 (Barcarrota) 2. ${ }^{a}$ ser., 1. a edic. Madrid: Instituto Geológico y Minero de España.

Murrieta-Flores, P.; García Sanjuán, L. y Wheatley, D. (2011): "Movilidad y vías de paso en los paisajes prehistóricos: Megalitos y vías pecuarias en Almadén de la Plata (Sevilla, España)”. En Mayoral, V. y Celestino, S. (eds.): Tecnologías de Información Geográfica y Análisis Arqueológico del Territorio (Actas V Symposio Internacional Arqueología de Mérida, 2007). Anejos de Archivo Espańol de Arqueología, 59. Madrid: csic, pp. 412-423.

Oliveira Jorge, V. (1991): "Arqueología social dos sepulcros megalíticos atlánticos: conhecimento e perspectivas actuais”. En Oliveira Jorge, S. y V.: Incurçôes na Préhistoria. Porto: Fundação Eng. Antonio de Almeida, pp. 57-152

Prada, A. y Cerrillo, E. (1996-2003): "Megalitismo y poblamiento neolítico en el suroeste de Badajoz: una lectura complementaria”, Norba, 16, pp. 47-74.

Queiroz, P. F. (2001): "Estudos de arqueobotánica sobre materiais provenientes da Anta 2 de Santa Margarida". Anexo en Gonçalves, V.: "A Anta 2 da Heredade de Santa Margarida (Reguengos de Monsaraz)", Revista Portuguesa de Arqueologia, 4 (2), pp. 186-190.

Rada y Delgado, J. y Vilanova y Piera, J. (1890): "Geología y Protohistoria Ibéricas". En Historia General de España escrita por individuos de Número de la Real Academia de la Historia bajo la dirección de Antonio Cánovas del Castillo. Madrid: El Progreso editorial.

Rocha, L. (2009/2010): "As origens do megalitismo funerario alentejano. Revisitando Manuel Heleno”, Promontoria, anos 7/8 nuevos, pp. 45-99.

SAnjuÁn, M. T. (2006): "Conjunto megalítico de la Dehesa Monteporrino de Salvaleón (Badajoz)", Revista de Estudios Extremeños, 62 (1), pp. 87-104.

Schubart, H. (1973): "Tholos-Bauten von Colada de Monte Nuevo bei Olivenza (prov. Badajoz)”, Madrider Mitteilungen, 14, pp. 11-40.

Villanueva, L. (1894): "Estación prehistórica de Badajoz", Boletín de la Real Academia de la Historia, XxIv (v), pp. 379-382. 